\title{
A movimentação das palavras: devir-construção no feminino da escrita
}

\author{
Jimena de Garay Hernández ${ }^{\text {Orcid, I, } \star ~ F l a v i o ~ L o p e s ~ G u i l h o n ~}{ }^{\text {Orcid, II }}$ \\ ${ }^{I}$ Universidade do Estado do Rio de Janeiro, Rio de Janeiro, RJ, Brasil \\ ${ }^{I I}$ Universidade Federal Fluminense, Niterói, RJ, Brasil
}

\begin{abstract}
Resumo
O presente trabalho, baseado em uma revisão teórica e em experiências de pesquisa acadêmica e de atuação das autoras junto a pessoas e famílias LGBT e a pessoas em privação de liberdade, levanta algumas possibilidades e desafios presentes na construção da escrita cartográfica. Uma escrita que, no exercício das problematizações do que tem sido naturalizado nas articulações de saber, poder e ética, se constitui enquanto um processo onde se afirmam tanto um novo paradigma ético-estético quanto um ato político e de resistência. A escrita cartográfica, no campo de luta, pode reverberar em revoluções moleculares, produzindo assim novos territórios de existência e táticas de singularização. Apostamos que essa escrita coletiva, atenta, minoritária, pode capturar movimentos sem, no entanto, aprisioná-los, e que esta pode ser entendida como uma máquina de guerra a produzir transformações tanto no próprio sistema linguístico quanto no cotidiano de nossas práticas de pesquisa, profissionais, políticas e de Vida.
\end{abstract}

Palavras-chave: escrita; revolução molecular; subjetivação; cartografia.

\section{The movement of words: becoming-construction in the feminine of writing}

\section{Abstract}

This paper, based on a literature review and the authors' research and work experiences with LGBT people and families and persons deprived of liberty, raises some possibilities and challenges present in the construction of cartographic writing. A writing that, in the exercise of the problematizations of what has been naturalized in the articulations of knowledge, power and ethics, is constituted as a process where both a new ethical-aesthetic paradigm and a political and resistance act claim. The cartographic writing, in the battlefield, may reverberate in molecular revolutions, thus producing new territories of existence and singularization tactics. We believe that this collective, attentive, minority writing can capture movements without, however, imprisoning them, and that it can be understood as a war machine that produces changes both within the linguistic system as in our everyday research, professional, political and Life practices.

Keywords: writing; molecular revolution; subjectivation; cartography.

\section{Iniciando uma conversa}

...escrever é o modo de quem tem a palavra como isca: a palavra pescando o que não é palavra. Quando essa não-palavra - a entrelinha-morde a isca, alguma coisa se escreveu. Uma vez que se pescou a entrelinha, poder-se-ia com alivio jogar a palavra fora. Mas ai cessa a analogia: a não-palavra, ao morder a isca, incorporou-a.

O que salva então é escrever distraidamente

(LISPECTOR, 1980, p. 21).

A ação de escrever nos convida a um mergulho no próprio processo da escrita. Sequenciar palavras de modo a construir um enunciado, apresentar uma ideia e suas afetações ou simplesmente construir novos territórios para que nossos pensamentos e emoções vagueiem são ações que se mesclam, se afetam e reinventam o processo de escrita, transformando aquilo que se sabe e apresentando novas formas de saber-fazer ou de fazer-saber, pois "escrevemos para transformar o que sabemos e não para transmitir o já sabido" (LARROSA; KOHAN, 2002, p. 5). Nesse sentido, a escrita pode ser entendida como um "campo de luta", ao fazer parte de um "modo de conhecer situado e engajado" (MORAES; BERNARDES, 2014).

\footnotetext{
^ Endereço para correspondência: Universidade do Estado do Rio de Janeiro. Avenida São Francisco Xavier, 524 - Maracanã, Rio de Janeiro, RJ - Brasil. CEP. 20550-900.E-mails: jime_degaray@hotmail.com, guilhon.flavio@gmail.com
}

Neste texto, pensamos nos movimentos do devir-construção na escrita, partindo do processo da escrita de nossas dissertações e teses no campo da Psicologia Social. Nelas, buscamos cartografar processos referentes aos dispositivos de gênero e sexualidade em filhas de lésbicas, de jovens homens em privação de liberdade e de pessoas LGBT acompanhadas no Centro de Cidadania LGBT, dispositivo ligado ao Programa Rio sem Homofobia, da extinta Secretaria Estadual de Assistência Social e Direitos Humanos do Rio de Janeiro.

Em uma cartografia, segundo Barros, R. (2013, p. 234), "o que se faz é acompanhar as linhas que se traçam, marcar os pontos de ruptura e de enrijecimento, analisar os cruzamentos dessas linhas diversas que funcionam ao mesmo tempo". Ainda acerca da cartografia, Rolnik (2011, p. 23) afirma que esta se desenha no mesmo tempo em que ocorre o desmanchamento de certos mundos, "mundos que se criam para expressar afetos contemporâneos, em relação aos quais os universos vigentes tornaram-se obsoletos", a partir dos novos desenhos cartográficos que vão sendo desenhados concomitantemente aos territórios que vão adquirindo corpo, pois um não existe sem o outro. Desse modo, cartografia se constitui como um mapa em constante processo de produção em que a experimentação sensível é contínua e capaz de criar novas coordenadas de leitura - e de escrita - da realidade, de forma que se questionem as hierarquias e fronteiras 
que dividem os campos de conhecimento e se proponha uma recriação permanente do campo de pesquisa (ZAMBENEDETTI; SILVA, 2011).

As experiências das autoras ao longo de suas trajetórias de vida e profissional as lançou para a produção de diferentes problematizações e encrencas no campo da discussão teórico-conceitual da sexualidade e do gênero. Tanto o que se refere à construção do feminino nos casos das mulheres transexuais ou de filhas de lésbicas quanto o que concerne à vivência do masculino dentro de uma unidade do sistema socioeducativo nos auxiliam a discutir, por um lado, as construções das relações de saber-poder e de afetividades, a partir de um feminino/ masculino que subverte os padrões hegemônicos e homogeneizantes. Ou seja, o modo como o gênero vai sendo constituindo em um corpo transexual, em uma família lesboparental e/ou em privação de liberdade, nos deram indícios para colocar em análise o modo como escrevemos e inscrevemos o gênero no texto e no corpo.

Destarte, tal como aconteceu nas nossas pesquisas, se a cartografia é não linear e não possui um roteiro que delimite suas entradas, passagens e saídas, se é cheia de aventuras, desafios, angústias, mudanças e afetações, a prática da escrita situada no ethos cartográfico percorre a habitação do campo de análise-intervenção, a criação de parcerias e alianças, o estabelecimento múltiplo de vínculos analíticos, os limites e potências do exercício de conceitos, a operação coletiva de movimentações e as implicações éticas, metodológicas e políticas (GARAY HERNÁNDEZ, 2018).

As experiências de pesquisa mencionadas nos remeteram, em diferentes momentos, a problematizar tanto aquilo que estava sendo escrito, incluindo o saber produzido, quanto o ato de escrever, na perspectiva de trilhar outros rumos para fugir das generalizações recorrentes ao campo acadêmico. Uma dessas generalizações corresponde à gramática portuguesa acerca do gênero feminino e masculino das palavras e consequentemente a todas as contradições existentes no sistema binário que acaba se refletindo e sendo produzido pela linguagem. E, ao não problematizar essas generalizações e contradições presentes na gramática portuguesa, transformando-as em questões a serem discutidas, corre-se o risco tanto de naturalizá-las quanto de perpetuar as violências por elas produzidas, seja quanto tomamos o masculino como universal, seja quanto tomamos o feminino como um lugar menor ou de menos valia.

Assim, uma aposta que de início se evidencia neste artigo é a de substituir a utilização generalista dos artigos definidos masculinos pela utilização dos artigos femininos, propondo que a totalidade seja percebida a partir das pessoas, de modo que a pluralidade das vivências, corporeidades e diversidade de gêneros não sejam homogeneizadas e invisibilizadas por uma certa universalidade masculina. Neste contexto, utilizaremos ao longo do texto artigos femininos enquanto uma aposta ética-estética-política de valorização do feminino, não no sentido edípico complementar e oposto do masculino, mas en- quanto devir-minoritário (BRAIDOTTI, 1996) e, portanto, de problematização da norma gramatical da língua portuguesa e da compreensão do mundo que ela instaura.

Se por um lado isso pode ser entendido como uma generalização às avessas, por outro podemos entender como uma tentativa de promover deslocamentos e dessencializações (e apostamos nisso), o que, numa perspectiva cartográfica, de imediato nos lançaria a um mergulho na experiência de pesquisar a partir da análise de nossas implicações e sensações. Seguindo Donna Haraway (1995, p. 584-585), podemos partir da proposição dos

conhecimentos situados, [que] sustentam a possibilidade de redes de conexões chamadas de solidariedade na política e de conversações compartilhadas na epistemologia, [exercitando uma] prática da objetividade [que] privilegia a contestação, a desconstrução, a construção apaixonada, as conexões em rede, e tem a esperança de transformar sistemas de conhecimento e formas de olhar.

É por isso que a escrita no feminino se produz na direção não de uma reificação material de Mulher, mas de um devir-minoritário, de uma "sujeita nômade de trajetórias coletivamente negociadas” (BRAIDOTTI, 1996, p. 314, tradução nossa).

Considerando a importância na cartografia da experiência no ato de pesquisar, Passos, Kastrup e Tedesco (2013, p. 217) sinalizam ser este o direcionador que "aponta sua inscrição no plano de forças, que constitui o plano de produção tanto do conhecimento quanto da realidade conhecida", e, no mesmo caminho, apostamos na realização destas reflexões sobre o processo da escrita, visto que uma pesquisa fala de e a partir da experiência, e consequentemente possibilita falas e produz conhecimentos. Neste sentido, as autoras sinalizam ser "necessário sublinhar que o ponto incontornável aqui é que a diretriz da investigação é o acesso/produção do plano de forças que responde pela criação/transformação da experiência" (PASSOS; KASTRUP; TEDESCO, 2013, p. 218).

Segundo Barros, R. (2013, p. 28), “escrever é lutar, resistir... é uma tarefa política" que pode ser entendida como um processo de construção de mundos e potencializadora da própria Vida, pois "escrever é cartografar, é a criação de territórios, estética da provisoriedade, constituição de panos de consciência, de onde a sujeita e objeto advêm". Ainda sobre a prática de escrever, a autora sinaliza que esta "é devir; é a estética da processualidade, dos acontecimentos que rompem a História, contato com o instante que suspende a continuidade temporal" (BARROS, R., 2013, p. 28).

Escrever é produzir, mas também se refere a felizes encontros e povoamentos. De acordo com Deleuze e Parnet (2004, p. 17), durante a produção estamos numa solidão absoluta, pois nesse momento

Não se pode fazer escola, nem fazer parte de uma escola. Há apenas trabalho nas trevas, e clandestino. Só que é uma solidão extremamente povoada. Não povoada de sonhos, de fantasmas nem de projetos, mas de encontros. Um encontro é talvez o mesmo que um devir ou umas núpcias. É do fundo dessa solidão que se pode dar qualquer encontro. 
Encontram-se pessoas (e por vezes sem as conhecer nem as ter jamais visto), mas também movimentos, ideias, acontecimentos, entidades.

Diante deste processo clandestino e povoado de encontros e possibilidades, nos vimos e sentimos duplamente roubadas, construindo e sendo construídas, por estas "novas maneiras de ler, e talvez mesmo de escrever” (DELEUZE; PARNET, 2004, p. 13). Deste modo, nos permitimos deslizar mais suavemente pelas letras $\mathrm{e}$ sílabas, pelas palavras e linhas, pelos parágrafos e textualidades produzidas nesta escrita, nos percebendo contagiadas pelo romantismo e fluidez, acessando, assim, cores, paisagens, afetos e a própria experiência, pois é "a experiência, e não a verdade, o que dá sentido à escritura" (LARROSA; KOHAN, 2002, p. 5).

Neste sentido, a experiência de escrever nos convoca a realizar cada vez mais encontros e mais transformações, considerando que o que anima o ato de escrever é a possibilidade de que "essa experiência em palavras nos permita liberar-nos de certas verdades, de modo a deixarmos de ser o que somos para ser outra coisa, diferentes do que vimos sendo" (LARROSA; KOHAN, 2002, p. 5). Libertação esta que nos aproxima de Andréa Zanella (2013, p. 19), ao propor uma perspectiva antropofágica para pensar e refletir sobre as mais diversas atrizes, sobretudo no que se refere aos modos de fazer-saber pesquisa, "ingerir, degustar, deglutir, digerir conceitos, hibridizar disciplinas, provocar fronteiras artificialmente impostas à realidade cambiante, complexa, mutável. Ampliar o debate psicológico, abrir possibilidades para várias outras aberturas e caminhos".

Deixar de ser o que somos para ser outra coisa nos remete ao devir, ao movimento e ao processo de vir a ser, pois, como sinalizam Deleuze e Parnet (2004, p. 12): "devir nunca é imitar, nem fazer como, nem uma sujeição a um modelo, seja ele de justiça ou de verdade, não há um termo de que se separe nem um ao qual se chegue ou ao qual se deva chegar". As ideias de processualidade e construção presentes nesta afirmação nos aproximam da preocupação que nos atravessa ao escrevermos, considerando a importância de pensar "como é que captamos os movimentos sem aprisioná-los", como sugere Uziel (2011, p. 20). Ou seja, a ideia de "devir" está ligada à possibilidade ou não de um processo de singularização (GUATTARI; ROLNIK, 2011).

Entendemos, tanto na realização deste trabalho quanto em nossas práticas cotidianas, o ato de escrever (e se inscrever no mundo) como um momento de criação que pode encontrar, aproximar e inventar diferentes conceitos. Consideramos o termo "conceito" como aquilo que é cheio de uma força crítica, política e de liberdade, visto que "é justamente a potência do sistema que pode, só ela, destacar o que é bom ou ruim, o que é novo ou não, o que está vivo ou não numa construção de conceitos" (DELEUZE, 1992, p. 46); sua potência nos remete à possibilidade de pensar sobre e como ele pode ser torcido e (re)adequado de acordo com o que produzimos.
Neste contexto, faz-se necessário, conforme sinaliza Deleuze (1992, p. 119-120),

primeiramente, ver e falar, mas com a condição de que o olho não permaneça nas coisas e se eleve até as 'visibilidades', e de que a linguagem não fique nas palavras ou frases e se eleve até o enunciados. É o pensamento como arquivo. Além disso, pensar é poder, isto é, estender relações de forçar, com a condição de compreender que as relações de força não se reduzem à violência, mas constituem ações sobre ações, ou seja, atos, tais como 'incitar, induzir, desviar, facilitar ou dificultar, ampliar ou limitar, tornar mais ou menos provável... É o pensamento como estratégia.

Utilizar o pensamento como estratégia possibilita que compreendamos as relações de forças que constituem ações, tornando provável ou possível pensar sobre a engrenagem molar e a revolução molecular. Ou seja, no plano molar, das formas e suas representações, das diferenças sociais mais amplas, da política, da constituição das grandes identidades, e no plano molecular, o plano das sensações, dos processos (GUATTARI; ROLNIK, 2011). Deste modo, podemos pensar em afetações moleculares, as quais são possíveis de serem produzidas com nossa escrita cotidianamente. Nesse campo, pensamos acerca dos desafios que nos envolvem, como pessoas que escrevem, produzindo novos territórios existenciais.

O processo de escrever está diretamente associado ao modo como as questões são fabricadas. Acerca do que envolve essas construções, Deleuze e Parnet (2004, p. 11) afirmam que,

as questões fabricam-se como qualquer outra coisa. Se não nos deixam fabricar nossas questões, com elementos vindos de toda a arte, não importa de onde, se apenas nos são colocadas, não temos grande coisa a dizer. A arte de construir um problema é muito importante: inventa-se um problema, uma posição do problema, antes de se encontrar uma solução.

Fabricar questões e construir problemas refere-se a problematizar o processo de escrita, considerando todas as linhas e forças que a atravessa e constitui.

\section{Problematizando a escrita}

O que eu tenho pontuado é isso: é o direito
da escrita e da leitura que o povo pede, que
o povo demanda. É um direito de qualquer
um, escrevendo ou não segundo as normas
cultas da língua. É um direito que as pessoas
também querem exercer.
Conceição Evaristo (2011)

Ao discutirem o ato de escrever, Deleuze e Parnet (2004, p. 60) apontam que:

Escrever é simples. Ou é uma maneira de se reterritorializar, de se conformar a um código de enunciados dominantes, a um território de estados de coisas estabelecidas [...] Ou, ao contrário, é tornar-se, tornar-se outra coisa que um escritor, já que, ao mesmo tempo, o que se torna torna-se outra coisa que não a escritura. Nem todo devir passa pela escritura, mas tudo o que se torna é objeto de escritura, de pintura ou de música. 
Dessa forma, para realizar este trabalho a partir de nossos questionamentos precisamos encontrar uma maneira pela qual, cada uma de nós, pudesse dialogar consigo mesma, com suas angústias e incertezas, e depois, juntas, nos arriscar a navegar na experiência uma da outra. Nesta maneira que não foi única, mas múltipla e muito transformadora, acessamos conversas repletas de vozes e muitas vezes cheias de silêncios e estranhamentos absolutos, tivemos que aprender a nos movimentar e capturar os movimentos sem capturá-los, como sinaliza Anna Uziel (2011).

Construir esta postura de estar no mundo numa constante análise das instituições, mas sobretudo das nossas implicações, concepções, certezas e dúvidas, nos levou ao estranhamento daquilo que se tornou tão familiar e naturalizado. Assim, por exemplo, ao partilharmos a análise crítica da Psicologia como campo de conhecimento tradicionalmente disciplinador (dos corpos, da sexualidade, da infância, da juventude, das famílias) e ao perceber que muitas vezes era nesse lugar que as participantes das pesquisas nos colocavam e até nós mesmas chegávamos a incorporar nas nossas ações, tentávamos incansavelmente colocar em análise e tentar deslocar esse lugar, gerando uma série de estranhamentos e incômodos, tanto nossos quanto das participantes. Esses incômodos e estranhamentos, enquanto experimentações, constituem dobras centrais das nossas pesquisas, já que os deslocamentos e problematizações das práticas fazem parte da cartografia enquanto intervenção, afirmando seu caráter político (COIMBRA; NASCIMENTO, 2008), e dessa forma permeiam nossa escrita, bem como as alianças que conseguimos estabelecer com outras psicólogas participantes das pesquisas, produzindo transformações coletivas na forma de se engajar pela potencialização da afirmação de vida, tanto na profissão quanto nas instituições em que atuamos.

Sobre estes incômodos, estranhamentos e deslocamentos, Sandra Azeredo (2010, p. 175) sinaliza que teorizar sobre gênero implica a produção de uma 'encrenca', especialmente para a Psicologia, "na medida em que essa é uma área disciplinar e a complexidade de gênero, segundo Judith Butler, exige um discurso inter e pós-disciplinar para resistir à domesticação acadêmica". Essa encrenca atravessa também os processos de pesquisa de campo e de escrita, pois, como sinalizado por Zanella (2013, p. 25), o estranhamento, quando acontece, possibilita "reconhecer o quão pouco vemos e o muito que há para ver nas paisagens que supostamente são conhecidas, nos detalhes que se revelam a olhares atentos, a olhares com formações diversas ou mesmo despretensiosas intenções".

Ao longo do acompanhamento de uma adolescente transexual, no Centro de Cidadania LGBT, cuja família procurou pelo serviço com a demanda de "curarmos o filho, que havia resolvido virar mulher", percebemos as tensões, confusões e encrencas que foram se apresentando no decorrer desse processo de transformação. As tensões e violências que emergiram por conta da construção desse corpo feminino, ao qual, inicialmente, recaíram expectativas referentes a uma vivência masculina, nos possibilitou presenciar os desafios que foram sendo apresentados a esta adolescente, cujo corpo e gênero subverteram e desorga- nizaram um certo funcionamento familiar e escolar, mas que, em suas palavras, "colaboraram para me transformar na mulher que hoje sou, menos ingênua, mas mais conhecedora do lugar que posso ocupar, mesmo com todas as violências que marcam nossas vidas de mulheres trans".

Ao conseguirmos estranhar o familiar e o natural e, consequentemente realizarmos algumas análises, nos deparamos com algumas dúvidas e construímos novas interrogações. Sobre a dúvida, Pozzana (2013, p. 335) afirma que "quando transformada em problema, quando articulada, é criação e produção de pensamento, é mergulho na experiência porque é com o corpo que uma questão se faz". Barros, L. e Barros, M. (2013, p. 377), acerca da análise, salientam que o

movimento de interrogação que a análise viabiliza se efetiva na constituição de um plano de pesquisa que indaga as demandas presentes no campo de intervenção e as forças e acontecimentos considerados estranhos ou silenciados por serem tidos como impeditivos de uma pesquisa bem-sucedida.

Assim, desde uma escolha política por uma transformação social e a tentativa de fazer da escrita uma das ferramentas para essa transformação, é necessário manter as nossas práticas, olhares, ouvidos e mãos (que digitam) fluidos, abertos e em conexão com os movimentos da experiência do campo do/com/em que está se escrevendo e inscrevendo. Perspectiva que se abre e nos abre a pensar novas maneiras de fazer e produzir práticas. De acordo com Azeredo (2010, p. 183),

o novo jeito de fazer está no encontro com a diferença, no esvaziar-se de si mesmo, colocando o eu na narrativa, enfim, na invenção de novas práticas performativas que resistam à reiteração das normas que produzem o humano numa situação de dominação.

Assim, reportar as suspeitas das nossas próprias certezas cristalizadas e como elas são desestabilizadas e deslocadas no processo da pesquisa aparece como um elemento fundamental da escrita cartográfica. Estranhar, duvidar e interrogar refere-se a posturas diante desta viagem, com as quais, sozinhas em nosso refúgio e clandestinidade, fomos acessando e transformando experiências, interrogações, de modo a propor outros modos de escrever.

Pensar nosso modo de escrita e consequentemente o modo como seu conteúdo tem sido redigido, assim como nossos questionamentos e como estes têm sido pesquisados, dizem de apostas éticas, estéticas e políticas que carregamos em nossos corpos, práticas e convicções de vida.

Em pesquisa com meninas, jovens e adultas filhas de lésbicas, uma família chamou particularmente a atenção pela multiplicidade de relações, vínculos e subjetividades, transbordando as noções tradicionais de organização familiar. Desta forma, na hora de experimentar o desenho de uma "árvore genealógica" dessa família, composta por experiências de inseminação caseira, homossexualidade, transexualidade, casamentos e amizades, foi necessária a criação de linhas, figuras e cores diversificadas, produzindo uma imagem que muito mais se parecia a um rizoma do que a uma árvore. O "rizoma genealógico" integrou a dissertação, com suas cores e figuras, e o próprio 
campo de pesquisa e seu mapeamento inventivo acionaram e operacionalizaram o campo conceitual e analítico que embasaram a pesquisa.

Nesse sentido, a aposta na estética como capacidade de criação no exercício da escrita, assim como dos corpos das mulheres transexuais e das relações familiares de mulheres lésbicas, aparece como parte importante desse processo. Por exemplo, a proliferação de títulos e subtítulos criativos e instigantes, muitas vezes provindos de falas de participantes da pesquisa, nos textos cartográficos se configura como uma arte que gera convites à leitura, no momento em que o título faz perguntas, não traz respostas anunciadas do que será lido, produzindo movimentos e deslocamentos. Perguntas que fazem da experiência da escrita e da leitura um processo coletivo, com um diálogo entre as vozes que escrevem, que leem, que citam, que indicam, que comentam, que questionam, nos lançando a novas descobertas e à construção de novos caminhos.

\section{Encontros e descobertas: novas formas de escrever}

Mapas... Localizadores espaciais que, ao mesmo tempo em que podem auxiliar quem os sabe ler, podem bloquear descobertas; orientadores de trajetórias que seguem a lógica do ponto de chegada, mas que podem ao mesmo tempo cegar. Quem pode com estes se orienta às vicissitudes dos percursos, à riqueza dos caminhos e à vida que os singulariza. Andréa Zanella (2013, p. 37).

Ao nos arriscarmos mergulhar na experiência que envolve o processo de escrita deparamo-nos com diferentes encontros e diálogos, (re)construímos caminhos e reinventamos problematizações, em eterna descoberta e movimentação rítmica, onde uma "dupla-captura" acontece. Conforme sinaliza Zanella (2013, p. 21),

problematizar o pesquisar como processo de criação e a pesquisa realizada como objetivação de uma atividade criadora que se apresenta com o obra a ser lida, degustada, devorada, deglutida. Obra que reinventa a própria vida, em vez de somente explicá-la ou compreendê-la. Testemunho de um fazer ciência para o qual não há álibi: não se apresenta o discurso do método singular como seu fundamento, mas as escolhas éticas e estéticas do pesquisador que se reinventa, bem como a realidade investigada no próprio processo de pesquisar.

Transformarmos a realidade investigada através de outra forma de fazer ciência, pautada em escolhas éticas, estéticas e políticas e na análise dessas escolhas. Tracejamos e seguimos linhas e viajamos por movimentos e sons, na perspectiva de construir outras melodias, produzindo novos territórios, como sugere Rolnik (2011), quando o fluxo de intensidades, ao escapar do plano de organização de territórios, canaliza as intensidades, dando-lhes novo sentido e construindo outras cartografias psicossociais.

Novos desenhos cartográficos psicossociais que nos remetem aos mapas, que, segundo Deleuze (1997, p. 8687), "não devem ser compreendidos só em extensão, em relação a um espaço constituído por trajetos", considerando a existência "também [de] mapas de intensidade, de densidade, que dizem respeito ao que preenche o espaço, ao que subtende o trajeto". Neste contexto, o mapa, segundo Deleuze e Guattari (1995, p. 30),

contribui para a conexão dos campos, para o desbloqueio dos corpos sem órgãos, para sua abertura máxima sobre um plano de consistência. Ele faz parte do rizoma. O mapa é aberto, é conectável em todas as suas dimensões, desmontável, reversível, suscetível de receber modificações constantemente. Ele pode ser rasgado, revertido, adaptar-se a montagens de qualquer natureza, ser preparado por um indivíduo, um grupo, uma formação social.

Ao tracejarmos pontos e compormos mapas, estamos seguindo linhas de modo a, como sinalizam Deleuze e Guattari (1995, p. 28), “escrever, fazer rizoma, aumentar seus territórios por desterritorialização, estender a linha de fuga até o ponto em que ela cubra todo o plano de consistência em uma máquina abstrata". Escrita enquanto ato político e máquina abstrata a produzir novos territórios de existência.

Por exemplo, incorporar trechos do diário de campo na escrita das dissertações e teses possibilita trazer de forma significativa à análise os percursos afetivos, políticos e metodológicos da pesquisa. Como apontado por Coimbra e Nascimento (2012, p. 131), o diário de campo é um dispositivo importante para a análise de implicação, pois

trabalha com o cotidiano da pesquisa, historicizando-o, registrando-o, potencializando-o; ou seja, incluindo-o naquilo que normalmente fica fora dos relatos considerados científicos. [...] A escrita do diário de campo é, portanto, uma potente ferramenta para que esses acontecimentos ignorados, tidos como perturbadores e desviantes, sejam problematizados.

Nesse sentido, trazer fragmentos do diário de campo possibilita sentir texturas das vivências e processos de experimentação. Como apontado por Lazzarotto e Carvalho (2012, p. 25), estarmos afetadas pelo acontecimento no ato de pesquisar "marca uma condição indispensável do processo de pesquisar: a capacidade de afetar e afetar-se para que se criem os modos de expressar os sentidos de uma pesquisa".

É assim que uma "escrita implicada" faz sentido. Aquela que tenta captar, "no dia a dia, as percepções, as experiências vividas, os diálogos, mas também as sobras do concebido que emergem" (HESS; WEIGAND, 2006, p. 16), que contém um projeto político das pesquisadoras de "transformar a si e a seu lugar social, a partir de estratégias de coletivização das experiências e análises" (LOURAU, 1993, p. 84-85). Uma escrita "calorosa", "espontânea", "sob o efeito do impacto dos acontecimentos", "transversal", que "explora a complexidade" (HESS; WEIGAND, 2006, p. 18/20), que dá conta das emoções ou paixões envolvidas no processo e procura produzir efeitos éticos, políticos e estéticos no campo e em si mesma a partir das movimentações, rupturas e desterritorializações das palavras, tornando-as acontecimentos. 
A escrita com várias mãos: quem escreve e para quem? Este livro não foi escrito apenas a quatro mãos (...). $\mathrm{Na}$ verdade, muitas mãos o escrevem. Suely Rolnik (2011, p. 15)

A experiência da escrita na cartografia é sempre feita a muitas mãos, como sugere Rolnik ao apresentar o livro "Micropolítica: cartografias do desejo" (GUATTARI; ROLNIK, 2011); apresenta um desafio ao paradigma científico que tem a ver com o fazer coletivo do processo da pesquisa. Sob nossa perspectiva, o campo de experimentação sensível que envolve uma pesquisa cartográfica dificilmente é percorrido apenas por uma pessoa. Equipe de pesquisa, colegas, orientadora, pares e, sobretudo, as pessoas que compõem o campo fazem parte das problematizações e propostas feitas no processo, pelo que elas são também interlocutoras/escritoras. É com e para todas essas pessoas que escrevemos, com o intuito de que essa escrita tenha reverberações que vão além dos pontos de entrada que imaginamos no início.

Diante dessa noção, nos deparamos com uma questão: em textos assinados por uma pessoa, tal como a dissertação, escrevemos como "eu" ou como "nós"? Nesse sentido, é importante refletir sobre o conceito de dissolução do ponto de vista da pesquisadora, um dos eixos da pesquisa cartográfica e que resulta extremamente desafiante, pois solicita que a pesquisadora não se localize na posição de observadora distante nem que localize um objeto como coisa idêntica a si mesma, mas que ponha em xeque os pontos de vista proprietários e os territórios existenciais solidificados, que se lance de forma performática na experiência, acompanhando os processos de emergência, que procure um paradigma de cuidar e conhecer como inseparáveis na transformação social que procura no momento em que pesquisa (PASSOS; DO EIRADO, 2009).

Ou seja, essa dissolução não significa deixar de existir, mas investir em uma existência de afetação e sensibilidade com os fluxos que o campo traz. Desta forma, mesmo trazendo as outras participantes da pesquisa ao processo de escrita, é importante não nos considerarmos onipotentes ao pensar que todas as ideias colocadas nos textos teriam sido construídas da mesma forma por essas outras pessoas, mas o nosso investimento na sensibilidade para ser atravessada por elas faz com que a escrita tente dar conta também dos seus próprios investimentos. Logo, uma possibilidade pode ser transitar entre o "eu", nos momentos em que consideramos pertinente trazer a nossa posição particular de sujeita atravessando o campo e as implicações que essa posição coloca, e o "nós", nos momentos em que as problematizações foram construídas coletivamente e o plano comum foi experimentado.

Em tese provinda de uma pesquisa realizada em uma unidade masculina de internação do sistema socioeducativo do Rio de Janeiro, o fato de a pesquisa ter sido realizada por uma equipe grande trouxe uma riqueza incomensurável, ao mesmo tempo em que apresentou desafios na hora de embarcar na produção de uma tese localizada em uma pessoa singular. A polifonia permeou todo o material de campo: gravações de reuniões na uni- versidade e de conversas no caminho de volta da unidade e de outros espaços do sistema, entrevistas realizadas não apenas pela doutoranda, relatos escritos em plataformas virtuais onde cada pesquisadora diferenciava com uma cor específica suas contribuições, anotações de eventos acadêmicos e políticos, bem como artigos, relatórios e outros textos coletivos escritos antes de a tese ser finalizada. Isto foi necessariamente incorporado na tese, apontando em cada momento a particularidade das reflexões propostas, na tentativa de potencializar essas polifonias.

Outra questão a ser considerada é a forma em que a escrita incorpora as vozes das participantes do campo, que não estão restritas aos momentos das entrevistas gravadas e das quais extraímos trechos a serem situados de forma separada no texto, mas proliferam nas nossas imersões no campo, em momentos não gravados, em gestos que não aparecem nas gravações, em sensações sentidas e experimentadas nos encontros. Inclusive, como nos instiga Despret (2011a), é possível questionar a naturalidade dada no campo das ciências humanas à necessidade da manutenção de um anonimato das participantes, como se isso lhes garantisse a proteção, quando na verdade pode auxiliar na instauração da assimetria de poder entre pesquisadora - a "expert" - e participantes, no que tange à diferença na sua responsabilização sobre os procedimentos e os conhecimentos que estão sendo produzidos. Isto, no entanto, continua sendo um desafio para as atuais políticas de pesquisa e em alguns contextos específicos em que elas se desenvolvem, tais como estabelecimentos de privação de liberdade, pois "como construir coletivamente dentro de uma instituição que produz segregação e controle?" (LEITE, 2014, p. 804). Porém, outras ferramentas podem ser acionadas para possibilitar a expressão da pluralidade na produção de conhecimento.

No caso da pesquisa com jovens no sistema socioeducativo, a abertura a expressões particulares que produzem sentidos na "vida do crime" e "na cadeia" nos instigou a fugir de tendências elitistas e adultocêntricas de tradução dessas expressões para uma linguagem palatável no âmbito acadêmico ou ao seu isolamento enquanto "termos êmicos". Esse processo nos levou a elaborar planos comuns em que essas expressões dialogassem com nossas ideias, colocando-as em itálicas, tal como fazemos neste texto, sem correções ortográficas ou gramaticais, por exemplo, no caso da expressão "oprimição". Também nos vimos convidadas a produzir eixos analíticos a partir dessas expressões e formular a escrita a partir delas, por exemplo, ao acionar o conceito de "sujeito homem" e seus múltiplos sentidos para explorar as performatividades masculinas. Para além de ser um analisador, "sujeito-homem" virou dispositivo de escrita, engrenando instituições, modos de subjetivação, encontros entre pesquisadoras e participantes, criação de territórios existenciais. Ao apostarmos que o processo de escrita pode reorganizar territórios e construir novas cartografias, enfatizamos que "o conhecimento a ser produzido e compartilhado pela pesquisa abrange as zonas de ambiguidades,

Fractal, Rev. Psicol., v. 31 - n. 1, p. 43-50, 2019 
acolhendo a experiência sem desprezar nenhuma de suas faces, seja a da objetividade, seja a da subjetividade" (BARROS, L.; BARROS, M., 2013, p. 375).

Quando consideramos todas as faces da experiência no processo de pesquisa, apostamos na possibilidade do acontecimento, que consiste

em remontar-se nele como num devir, em nele rejuvenescer e envelhecer a um só tempo, em passar por todos os seus componentes ou singularidades. O devir não é história; a história designa somente o conjunto das condições, por mais recentes que seja, das quais desvia-se a fim de 'devir', isto é, para criar algo novo (DELEUZE, 1992, p. 211).

\section{As revoluções moleculares escritas e as escritas molecularmente revolucionárias}

Como ouvi conversas de mulheres! Falar e ouvir entre nós era talvez a única defesa, o único remédio que possuíamos. Venho de uma família em que as mulheres, mesmo não estando totalmente livres de uma dominação machista, primeiro a dos patrões, depois a dos homens seus familiares, raramente se permitiam fragilizar. Como 'cabeça' da família, elas construíam um mundo próprio, muitas vezes distantes e independentes de seus homens e mormente para apoiá-los depois. Talvez por isso tantas personagens femininas em meus poemas e em minhas narrativas? Pergunto sobre isto, não afirmo. Conceição Evaristo (2005, p. 4).

Vinciane Despret (2011b) chama a atenção à importância da articulação entre emoção e política - enquanto relações de poder - e propõe que a construção do problema de pesquisa se dê junto com o conhecimento do campo, dando à pesquisadora a possibilidade de transformação no próprio processo de investigação.

Ao ser a cartografia, enquanto método de pesquisa-intervenção, constituída pelo devir, pelo movimento, pela atenção, pela busca de irregularidades e surpresas que produzem mundo (LEITE, 2014), apostamos no processo da escrita coletiva e, por conseguinte, feliz, entendendo que esta se transforma numa máquina de guerra e em um texto que funciona como um ato de resistência, uma tarefa política e uma cartografia que segue criando territórios pois, como afirma Barros, R. (2013, p. 28), “escrever é devir; é a estética da processualidade, dos acontecimentos que rompem a História, contato com o instante que suspende a continuidade temporal".

Igualmente, podemos enxergar a reflexão da escrita cartográfica em conexão com a noção de "revolução molecular" entendida por Guattari e Rolnik (2011), como um processo de diferenciação e resistência ao controle social. As revoluções moleculares são produções de condições de vida coletiva e subjetiva que se constituem em todos os níveis: infrapessoais (sonhos, criações), pessoais (relações de autodominação) e interpessoais (a invenção de formas de sociabilidade na vida doméstica, profissional, local e escolar). Desta forma, as nossas escolhas políticas não são apenas uma resistência contra um processo de serialização da subjetividade, "mas a tentativa de produzir modos de subjetivação originais e singulares, processos de singularização subjetiva" (ROLNIK, 2011, p. 61).

Esses processos são caracterizados por serem automodeladores, ou seja, constroem seus próprios tipos de referências práticas e teóricas, sem depender constantemente dos poderes globais, econômicos e sociais. E essa autonomia e liberdade de viver os próprios processos produzem uma capacidade de criação e de insurgência. Se acionarmos essa capacidade nas tessituras das caminhadas investigativas, a escrita sendo parte fundamental delas, podemos experimentar os "devires revolucionários" como verbos em sua singularidade (GUATTARI; ROLNIK, 2011).

A escrita cartográfica, instaurada em uma perspectiva de abertura, atenção, confiança, processualidade, emoção, se abre aos curtos-circuitos do campo de pesquisa enquanto campo de diferenciação e desterritorialização, busca a criação, a multiplicação das conexões de formas de ser no mundo, tem como principal objetivo traçar planos em comum em que as diferenças não apenas sejam consideradas, mas que constituam as possibilidades de existência coletiva e singular, em que os conceitos sejam partilhados, inventados e também desestabilizados, sempre acompanhando processos, fazendo perguntas, abrindo caminhos, possibilitando que as revoluções moleculares do campo façam passagem pela escrita e ao mesmo tempo gerando possibilidades de singularização em um texto pulsante e potencializador. Como Deleuze e Guattari (1995, p. 32) apontam:

empregamos somente palavras que, por sua vez, funcionavam para nós como platôs. [...] Estas palavras são conceitos, mas os conceitos são linhas, quer dizer, sistemas de números ligados a esta ou àquela dimensão das multiplicidades (estratos, cadeias moleculares, linhas de fuga ou de ruptura, círculos de convergência, etc.).

Ao transitar e habitar territórios de pesquisa, de exercício profissional e de escrita, uma metodologia rizomática vai se constituindo a partir da noção de processualidade, da inversão, reflexão e modificação dos jogos de forças entre sujeitas/participantes, pesquisadoras, territórios e temporalidades, de modo que uma escrita no feminino, coletiva, descentrada, minoritária, cartográfica e revolucionária, possa emergir, nos apontando novos caminhos moleculares a serem descobertos, experimentados e vivenciados, pois,

Escrever é um caso de devir, sempre inacabado, sempre em via de fazer-se, e que extravasa qualquer matéria vivível ou vivida. É um processo, ou seja, uma passagem de vida que atravessa o vivível e o vivido. A escrita é inseparável do devir: ao escrever, estamos num devir-mulher, num devir-animal ou vegetal, num devir-molécula, até num devir-imperceptível (DELEUZE, 1997, p. 11). 


\section{Referências}

AZEREDO, Sandra. Encrenca de gênero nas teorizações em psicologia. Revista Estudos Feministas, Florianópolis, v. 18, n. 1, p. 175-188, 2010. Cross ${ }^{\text {Ref }}$

BARROS, Regina Duarte Benevides. Grupo: a afirmação de um simulacro. 3. ed. Porto Alegre: Sulina/UFRGS, 2013. Coleção Cartografias.

BARROS, Letícia Maria Renault de; BARROS, Maria Elizabeth Barros de. O problema da análise em pesquisa cartográfica. Fractal: Revista de Psicologia, Niterói, v. 25, n. 2, p. 373-390, maio/ago. 2013. Cross ${ }^{\text {Ref }}$

BRAIDOTTI, Rosi. Nomadism with a difference: Deleuze's legacy in a feminist perspective. Man and World, v. 29, n. 3, p. 305-314, 1996. Cross ${ }^{\text {Ref. }}$

COIMBRA, Cecília Maria Bouças; NASCIMENTO, Maria Lívia do. Análise de implicações: desafiando nossas práticas de saber/poder. In: GEISLER, Adriana Ribeiro Rice; ABRAHÃO, Ana Lúcia; COIMBRA, Cecília Maria Bouças (Org.). Subjetividades, violência e direitos humanos: produzindo novos dispositivos em saúde. Niterói: EdUFF, 2008. p. 143-153.

COIMBRA, Cecília Maria Bouças; NASCIMENTO, Maria Lívia do. Implicar. In: FONSECA, Tania Mara Galli; NASCIMENTO, Maria Lívia do; MARASCHIN, Cleci. (Org.). Pesquisar na diferença: um abecedário. Porto Alegre: Sulina, 2012. p. 129-131.

DELEUZE, Gilles. Conversações. Tradução de Peter Pál Pelbart. Rio de Janeiro: Ed. 34, 1992.

DELEUZE, Gilles. Crítica e clínica. Tradução de Peter Pál Pelbart. 2. ed. São Paulo: Ed. 34, 1997.

DELEUZE, Gilles; GUATTARI, Félix. Mil platôs: capitalismo e esquizofrenia. Tradução de Aurélio Guerra Neto e Celia Pinto Costa. São Paulo: Ed 34, 1995. v. 1. Coleção TRANS.

DELEUZE, G.; PARNET, C. Diálogos. Tradução de José Gabriel Cunha. Lisboa: Relógio D’Água, 2004.

DESPRET, Vinciane. A leitura etnopsicológica do segredo. Fractal: Revista de Psicologia, Niterói, v. 23, n. 1, p. 5-28, 2011a. Cross ${ }^{\text {Ref }}$

DESPRET, Vinciane. As ciências da emoção estão impregnadas de política? Catherine Lutz e a questão do gênero das emoções. Fractal: Revista de Psicologia, Niterói, v. 23, n. 1, p. 29-42, 2011b. Cross ${ }^{\text {Ref }}$

EVARISTO, Conceição. Gênero e etnia: uma escre(vivência) de dupla face. In: MOREIRA, Nadilza Martins; SCHNEIDER, Liane (Org.). Mulheres no mundo: etnia, marginalidade e diáspora. João Pessoa, PB: Ideia/UFPB, 2005. p. 201-212.

EVARISTO, Conceição. Conceição Evaristo: literatura e consciência negra. Blogueiras Feministas, 22 nov. 2011. Entrevista concedida a Bárbara Araújo. Disponível em: https:// blogueirasfeministas.com/2011/11/22/conceicao-evaristo/. Acesso em: 1 nov. 2018.

GUATTARI, Félix; ROLNIK, Suely. Micropolitica: cartografias do desejo. 11 ed. Petrópolis, RJ: Vozes, 2011.

GARAY HERNÁNDEZ, Jimena de. O Adolescente dobrado: cartografia feminista de uma unidade masculina do Sistema Socioeducativo do Rio de Janeiro. 2018. 442 f. Tese (Doutorado em Psicologia Social)-Programa de Pós-graduação em Psicologia Social, Universidade do Estado do Rio de Janeiro, Rio de Janeiro, 2018.
LISPECTOR, Clarice. Água viva. Rio de Janeiro: Nova Fronteira, 1980.

HARAWAY, Donna. Ciencia, cyborgs y mujeres: la invención de la naturaleza. Madrid: Cátedra, 1995.

HESS, Remi; WEIGAND, Gabriele. A escrita implicada. Revista Reflexões e Debates - Cadernos de educação, n. 11, p. 14-25, 2006.

LARROSA, Jorge; KOHAN, Walter (Coord). Apresentação. In: RANCIÈRE, Jacques. O mestre ignorante: cinco lições sobre a emancipação intelectual. Belo Horizonte: Autêntica, 2002. p. 5. Coleção Educação: Experiência e Sentido.

LAZZAROTTO, Gislei Domingas Romanzini; CARVALHO, Julia Dutra de. Afetar. In: FONSECA, Tania Mara Galli; NASCIMENTO, Maria Lívia do; MARASCHIN, Cleci. (Org.). Pesquisar na diferença: um abecedário. Porto Alegre: Sulina, 2012. p. 23-25.

LEITE, Maynar Patricia Vorga. Cartografar (n)a prisão. Estudos e Pesquisas em Psicologia, v. 14, n. 3, p. 795-813, 2014. Cross ${ }^{\text {Ref }}$

LOURAU, René. René Lourau na UERJ: Análise Institucional e Práticas de Pesquisa. Rio de Janeiro: EdUERJ, 1993.

MORAES, Marcia; BERNARDES, Anita Guazzelli. Apresentação. In: BERNARDES, Anita Guazzelli; TAVARES, Gilead Marchezi; MORAES, Marcia (Org.). Cartas para pensar: políticas de pesquisa em Psicologia. Vitória: EDUFES, 2014. p. 7-14.

PASSOS, Eduardo; DO EIRADO, André. Cartografia como dissolução do ponto de vista do observador. In: KASTRUP, Virginia; PASSOS, Eduardo; ESCÓSSIA, Liliana da. (Org.). Pistas do método da cartografia: pesquisa-intervenção e produção de subjetividade. Porto Alegre: Sulina, 2009. p. 109130.

PASSOS, Eduardo; KASTRUP, Virginia; TEDESCO, Silvia. Editorial v. 25, n. 2 - Dossiê Cartografia: pistas do método da cartografia - Vol. II. Fractal, Revista de. Psicologia, Niterói, v. 25 , n. 2, p. 217-220, maio/ago. 2013. Disponível em: http:// periodicos.uff.br/fractal/article/view/4939/4781. Acesso em: 10 out.2018.

POZZANA, Laura. A formação do cartógrafo é o mundo: corporificação e afetabilidade. Fractal, Revista de. Psicologia, Niterói, v. 25, n. 2, p. 323-338, maio/ago. 2013. Cross ${ }^{\text {Ref }}$

ROLNIK, Suely. Cartografia Sentimental: transformações contemporâneas do desejo. Porto Alegre: Sulina/UFRGS, 2011.

UZIEL, Anna Paula. Diversidade sexual, democracia e promoção de direitos. In: CONSELHO FEDERAL DE PSICOLOGIA (Org.). Psicologia e diversidade sexual: desafios para uma sociedade de direitos. Brasília: CFP, 2011. p. 13-24. Conferência.

ZAMBENEDETTI, Gustavo; SILVA, Rosane Azevedo Neves da. Cartografia e genealogia: aproximações possíveis para a pesquisa em psicologia social. Psicologia \& Sociedade, v. 23, n. 3, p. 454-463, set./dez. 2011. Cross ${ }^{\text {Ref }}$

ZANELLA, Andréa Vieira. Perguntar, registrar, escrever: inquietações metodológicas. Porto Alegre: Sulina/UFRGS, 2013.

Recebido em: 14 de outubro de 2015 Aceito em: 22 de novembro de 2018

Fractal, Rev. Psicol., v. 31 - n. 1, p. 43-50, 2019 